\title{
GH-induced LH hyporesponsiveness as a potential mechanism for hypogonadism in male patients with acromegaly
}

\author{
Rie Nishio ${ }^{1), 4)}$, Akira Takeshita ${ }^{1), 10)}$, Toyoyoshi Uchida $^{4)}$, Takashi Herai ${ }^{3)}$, Kenichi Sakamoto ${ }^{1), 6)}$, \\ Yuichiro Shimizu ${ }^{1), 7)}$, Makoto Arai ${ }^{8)}$, Keita Tatsushima ${ }^{1)}{ }^{10)}$, Noriaki Fukuhara ${ }^{2)}$ 10), Mitsuo Okada ${ }^{2)}$, \\ Hiroshi Nishioka $^{2), 10)}$, Shozo Yamada ${ }^{2), 5), 10)}$, Noriyuki Koibuchi ${ }^{9}$, Hirotaka Watada ${ }^{4}$ and \\ Yasuhiro Takeuchi ${ }^{1)}$,10) \\ 1) Department of Endocrinology and Metabolism, Toranomon Hospital, Tokyo 105-8470, Japan \\ 2) Department of Hypothalamic and Pituitary Surgery, Toranomon Hospital, Tokyo 105-8470, Japan \\ 3) Department of Clinical Laboratory, Toranomon Hospital, Tokyo 105-8470, Japan \\ 4) Department of Metabolism and Endocrinology, Juntendo University Graduate School of Medicine, Tokyo 113-8421, Japan \\ 5) Hypothalamic and Pituitary Center, Moriyama Memorial Hospital, Tokyo 134-0081, Japan \\ 6) Department of Endocrinology, Hematology, and Gerontology, Chiba University Graduate School of Medicine, Chiba 260-8670, \\ Japan \\ 7) Shimizu Clinic, Tokyo 107-0052, Japan \\ 8) Division of Molecular Physiology and Metabolism, Faculty of Medicine, Tohoku University, Miyagi 980-8575, Japan \\ 9) Department of Integrative Physiology, Gunma University Graduate School of Medicine, Gunma 371-8511, Japan \\ 10) Okinaka Memorial Institute for Medical Research, Tokyo 105-8470, Japan
}

\begin{abstract}
Male patients with acromegaly frequently have hypogonadism. However, whether excess GH affects gonadal function remains unclear. We retrospectively compared clinical features affecting total testosterone (TT) and free testosterone (FT) levels between 112 male patients with acromegaly and 100 male patients with non-functioning pituitary adenoma (NFPA) without hyperprolactinemia. Median maximum tumor diameter (14.4 vs. $26.5 \mathrm{~mm})$ and suprasellar extension rate (33 vs. $100 \%$ ) were lower in acromegaly, but LH, FSH, TT, and FT were not significantly different. In acromegaly, TT was less than $300 \mathrm{ng} / \mathrm{dL}$ in $57 \%$, and FT was below the age-specific reference range in $77 \%$. TT and FT were negatively correlated with GH, IGF-1, and the tumor size, and positively correlated with LH. In NFPA, they were positively correlated with IGF-1, LH, FSH, ACTH, cortisol, and free T4, reflecting hypopituitarism. Multiple regression analysis showed that TT and FT had the strongest correlation with GH in acromegaly, and with LH in NFPA. Surgical remission was achieved in $87.5 \%$ of 56 follow-up patients with acromegaly. TT and FT increased in 80.4 and $87.5 \%$, respectively, with a significant increase in LH. In acromegaly, the degree of postoperative increase in TT(FT) correlated with the fold increase of TT(FT)/LH ratio, a potential parameter of LH responsiveness, but not with fold increase of LH, whereas in NFPA it correlated with both. These results suggest that excessive GH is the most relevant factor for hypogonadism in male acromegaly, and may cause impaired $\mathrm{LH}$ responsiveness as well as the suppression of LH secretion.
\end{abstract}

Key words: Acromegaly, Hypogonadism, Growth hormone, Luteinizing hormone, Testosterone

PATIENTS with acromegaly, which is caused by GH hypersecretion from a GH-producing pituitary adenoma, frequently have hypogonadism [1, 2]. Several mechanisms have been proposed as causes of acromegalyrelated hypogonadism, including reductions in the

Submitted Sep. 17, 2020; Accepted Mar. 8, 2021 as EJ20-0596 Released online in J-STAGE as advance publication Apr. 9, 2021 Correspondence to: Akira Takeshita, Department of Endocrinology and Metabolism, Toranomon Hospital, 2-2-2 Toranomon, Minato, Tokyo 105-8470, Japan.

E-mail: coactivator@mac.com secretion of LH and/or FSH due to the pituitary tumor mass effect [3-5] and the effects of concomitant hyperprolactinemia for the suppression of GnRH [6] and $5 \alpha-$ reductase enzyme activity [7]. However, hypogonadism is common among acromegaly patients with microadenoma that do not cause the tumor mass effect as well as in those without concomitant hyperprolactinemia [1]. A previous study reported that total testosterone (TT) and DHT levels were significantly lower in male patients with acromegaly without hyperprolactinemia than in agematched normal subjects and also that serum GH and 
IGF-1 levels inversely correlated with DHT levels [2]. Moreover, TT, DHT, and the number and motility of sperm increased after disease control by surgery or a treatment with lanreotide [2]. Therefore, excess GH itself may play an important role in the pathogenesis of hypogonadism in patients with acromegaly independent of gonadotropin and prolactin (PRL) levels.

Under physiological conditions, GH is important for gonadal development in children and the maintenance of gonadal function in adults $[8,9]$. GH receptor immunoreactivity was detected in Leydig and Sertoli cells [9, 10]. Both GH deficient and GH receptor knockout mice had fewer LH/CG receptors in Leydig cells $[11,12]$, and the former reduction recovered by GH supplementation [11]. In GH receptor knockout mice, LH-stimulated testosterone production of the cultured testes was reduced, indicating that $\mathrm{GH}$ enhanced the physiological response of LH-stimulated testosterone secretion from Leydig cells [13]. GH receptor immunoreactivity was also detected in gonadotrophs in the anterior pituitary gland [14], suggesting that GH may modulate gonadotropin secretion. In the clinical setting, the sperm count of patients with adult GH deficiency decreased, but recovered by chronic GH supplementation [15]. Therefore, the physiological secretion of GH may play an important role in the synthesis of testosterone, with deficient and excess $\mathrm{GH}$ both causing male hypogonadism.

Large-scale studies to identify the critical factors influencing hypogonadism in male acromegaly have not yet been conducted. Therefore, we herein investigated the clinical characteristics influencing TT and free testosterone (FT) in untreated male patients with acromegaly in comparisons with male patients with nonfunctioning pituitary adenoma (NFPA).

\section{Materials and Methods}

\section{Patients}

A total of 181 consecutive Japanese adult male patients (aged 21-59 years) with acromegaly at Toranomon Hospital in Tokyo between 2009 and 2015 were retrospectively examined. A clinical diagnosis of acromegaly was reached based on the following clinical criteria [16]: specific physical findings of the disease, elevated $\mathrm{GH}$ levels, not suppressible to lower than $0.4 \mathrm{ng} / \mathrm{mL}$ after the $75 \mathrm{~g}$ oral glucose tolerance test (OGTT), high IGF-1 levels for age, and pituitary magnetic resonance imaging (MRI) findings. A definitive diagnosis was confirmed using a pathological evaluation, including immunohistochemical staining for GH. Among the 181 patients, 24 with a PRL level higher than the upper limit of the reference range $(31.2 \mathrm{ng} / \mathrm{mL}), 34$ who were treated medically at referral hospitals, 9 with recurrent acromegaly after surgery, and 2 with pituitary apoplexy were all excluded. Thus, 112 patients were enrolled in the present study; 19 received a short-term preoperative somatostatin analog (SSA) treatment for $39.6 \pm 13.3$ days (mean \pm SD) (15 received octreotide $\mathrm{LAR}$, and 4 received lanreotide autogel).

As a control, 126 consecutive male adult Japanese patients (aged 21-59 years) with surgically treated clinically NFPA at Toranomon Hospital between 2011 and 2015 were retrospectively examined. None of the 126 patients had received androgen replacement therapy before surgery. Among these patients, 26 (8 recurrent cases after surgery, 13 with PRL higher than the upper limit of the reference range $(31.2 \mathrm{ng} / \mathrm{mL})$ and/or 4 with immunohistochemically diagnosed silent TSH adenoma, 2 with silent plurihormonal pituitary adenoma, and 1 with silent GH adenoma) were excluded. Therefore, 100 patients with NFPA of either gonadotroph adenoma or hormone-negative adenoma were used as a control.

The present study was approved by the Institutional Review Board of Toranomon Hospital (approval number, 1781).

\section{Measurement of serological data}

The following laboratory blood data were simultaneously obtained before surgery and retrospectively collected for all 112 patients with acromegaly: GH, IGF-1, LH, FSH, TT, FT, PRL, TSH, Free T4, ACTH, and cortisol. Postoperative blood data were simultaneously collected between 6 and 12 months after surgery in 56 patients who were followed up for more than 6 months after surgery. No patient with acromegaly had received hydrocortisone or thyroxine replacement therapy before or after surgery. Among 100 patients with NFPA, FT data was missing in one and two before and after surgery, respectively. Postoperative blood data on NFPA were simultaneously collected between 6 and 12 months after surgery in 60 patients who were followed up for more than 6 months without androgen replacement therapy after surgery. To exclude data on ACTH, cortisol, TSH, and free T4, which are affected by hydrocortisone or thyroid hormone replacement therapy, data on ACTH and cortisol after the administration of hydrocortisone and on TSH and free T4 under thyroxine replacement therapy were omitted.

The LH-RH loading test in addition to the TRH and CRH loading tests (a triple test) were performed before and after surgery. The postoperative triple test was conducted between postoperative days 7 and 14. In patients with NFPA, the triple test was rarely performed preoperatively due to the large size of the tumor and the high risk of pituitary apoplexy.

The surgical remission of acromegaly was defined as a 
normalized IGF-1 level 6 to 12 months after surgery with a random $\mathrm{GH}$ level lower than $1.0 \mathrm{ng} / \mathrm{mL}$ or a nadir $\mathrm{GH}$ level lower than $0.4 \mathrm{ng} / \mathrm{mL}$ after $75 \mathrm{~g}$ OGTT [17]. In 19 patients who received the preoperative SSA treatment, blood data before the treatment were used as preoperative data, and postoperative data were selected from tests that were performed after the effects of SSA had completely disappeared (i.e. more than 6 months after surgery).

Serum GH levels were measured using enzyme immunoassays (EIA) (Tosoh Corporation, Tokyo) between July 1, 2009 and December 30, 2013 and by electrochemiluminescence immunoassays (ECLIA) (Roche Diagnostics, Tokyo) from December 31, 2013. The regression analysis equation obtained from a comparison of $\mathrm{GH}$ results is as follows: $\mathrm{GH}$ (ECLIA) $=1.018 \mathrm{GH}$ (EIA) -0.18 ( $n=101, r=0.997)$. Serum IGF-1 levels were measured by immunoradiometric assays (IRMA) (Fujirebio Corporation, Tokyo). Each serum IGF-1 value was transformed into an age- and sex-adjusted standardized curve score (IGF-1 Z-score) based on a previous study on the reference intervals of serum IGF-1 values in a healthy Japanese population [18]. Serum LH levels were measured by chemiluminescent enzyme immunoassays (CLEIA) (Fujirebio Corporation; reference range, 1.4-8.2 IU/L) and FSH levels by CLEIA (Fujirebio Corporation; reference range, 2.1-12.1 IU/L). Serum TT levels were measured by ECLIA (Roche Diagnostics) between July 1, 2009 and December 2, 2010, and by ECLIA (Roche Diagnostics) from December 3, 2010. Serum TT levels measured using the previous method (X) were converted to the latest method (Y) equivalents using the following formula: $\mathrm{Y}(\mathrm{ng} / \mathrm{dL})=1.040 \times(\mathrm{X}$ $[\mathrm{ng} / \mathrm{dL}])-0.078(n=147, r=0.992)$. Serum FT levels were measured by radio immunoassays (RIA) (LSI Medience Corporation; reference range, Supplemental Table 1). Serum PRL levels were measured by CLEIA (Fujirebio Corporation, Tokyo; reference range, 4.4$31.2 \mathrm{ng} / \mathrm{mL}$ ), TSH levels by CLEIA (Fujirebio Corporation; reference range, $0.54-4.26 \mu \mathrm{IU} / \mathrm{mL}$ ), and Free T4 levels by CLEIA (Fujirebio Corporation; reference range, 0.72-1.52 ng/dL). Serum ACTH levels were measured by ECLIA (Roche Diagnostics; reference range, $7.2-63.3 \mathrm{pg} / \mathrm{mL}$ ) and cortisol levels by ECLIA (Roche Diagnostics; reference range, 4.5-21.1 $\mu \mathrm{g} / \mathrm{dL}$ ). We used a half level of the lower limit level in samples, which was lower than the sensitivity of the measurement (TSH before surgery and GH after surgery).

\section{Measurement of maximum mass diameter}

All patients underwent pituitary contrast-enhanced MRI before surgery. We obtained sagittal, coronal, and axial views and measured the maximum tumor diameter.

\section{Primary outcome}

The primary outcome of the present study was to identify clinical parameters that correlate with the hypogonadal biomarker TT and FT in male patients with untreated acromegaly without concomitant hyperprolactinemia.

\section{Statistical analysis}

Results are presented as means \pm SD for normally distributed parameters and as medians with interquartile ranges (IQR) for parameters with skewed distributions. Data on the latter parameters were transformed to logarithmic data before being used in statistical analyses. Regarding differences in physical signs, various endocrinological parameters were examined for significant changes using the Student's $t$-test or Mann-Whitney $U$ test, where appropriate. The assumption of multicollinearity was assessed by Pearson's correlation coefficient among independent variables. To identify factors that correlate with TT and FT levels in untreated acromegaly patients, independent variables were submitted to a multivariate regression analysis. Due to positive correlations between GH and IGF-1 $(r=0.533, p<0.001)$, GH and the maximum tumor diameter $(r=0.565, p<0.001)$, and LH and FSH $(r=0.621, p<0.001)$, we also conducted the analysis in consideration of multicollinearity. The multicollinearity was all excluded despite positive correlations being observed. A $p$ value of $<0.05$ was considered to be significant. All statistical analyses were performed using the Statistical Package for the Social Sciences (Chicago, IL).

\section{Results}

The basal characteristics of the enrolled patients with acromegaly and NFPA are shown in Table 1 . The median age of patients with acromegaly was nine years younger than those with NFPA (40 vs. 49 years, $p<0.001)$. The median body mass index (BMI) was significantly higher in patients with acromegaly than in those with NFPA (25.6 vs. $\left.24.4 \mathrm{~kg} / \mathrm{m}^{2}, p=0.01\right)$. In patients with acromegaly, median $\mathrm{GH}$ was $12.4 \mathrm{ng} / \mathrm{mL}$ with high IGF-1 (Zscore, $7.70 \pm 2.57$ ). In contrast, in patients with NFPA, median $\mathrm{GH}$ was $0.10 \mathrm{ng} / \mathrm{mL}$ generally with low IGF-1 (Z-score, $-1.33 \pm 1.28)$. In addition, ACTH and free T4 were significantly lower in patients with NFPA than in those with acromegaly, indicating a higher frequency of complications associated with hypopituitarism in patients with NFPA. In patients with acromegaly, the median LH level was low normal (2.2 IU/L, IQR 1.5-3.5 IU/L). The median TT was $263 \mathrm{ng} / \mathrm{dL}$, and 43 (38.4\%) and 64 (57.1\%) out of 112 patients met the hypogonadism criterion of TT lower than $230 \mathrm{ng} / \mathrm{dL}$ [19] and $300 \mathrm{ng} / \mathrm{dL}$ 
Table 1 Comparison of clinical characteristics between patients with acromegaly and non-functioning pituitary adenoma

\begin{tabular}{|c|c|c|c|c|c|}
\hline & \multicolumn{2}{|c|}{ Acromegaly $(n=112)$} & \multicolumn{2}{|c|}{$\operatorname{NFPA}(n=100)$} & \multirow{2}{*}{$p$} \\
\hline & Median (IQR) & Mean $\pm \mathrm{SD}$ & Median (IQR) & Mean \pm SD & \\
\hline Age (y.o.) & $40(33-50)$ & $41 \pm 10$ & $49(43-55)$ & & $<0.001^{\dagger \dagger a}$ \\
\hline $\operatorname{BMI}\left(\mathrm{kg} / \mathrm{m}^{2}\right)$ & $25.6(23.1-27.1)$ & & $24.4(22.4-26.4)$ & $24.5 \pm 2.8$ & $0.01^{\dagger \mathrm{a}}$ \\
\hline $\mathrm{GH}(\mathrm{ng} / \mathrm{mL})$ & $12.4(5.3-21.7)$ & & $0.10(0.05-0.29)$ & & $<0.001^{\dagger \dagger \mathrm{a}}$ \\
\hline IGF-1 (ng/mL) & $699(570-916)$ & $736 \pm 255$ & $108(88-140)$ & $114 \pm 42$ & $<0.001^{\dagger \dagger \mathrm{a}}$ \\
\hline IGF-1 (Z-score) & $7.65(5.83-9.34)$ & $7.70 \pm 2.57$ & $-1.22(-2.13--0.33)$ & $-1.33 \pm 1.28$ & $<0.001^{\dagger \dagger a}$ \\
\hline LH (IU/L) & $2.2(1.6-3.5)$ & & $2.1(1.4-3.0)$ & & 0.108 \\
\hline FSH (IU/L) & $7.9(5.7-11.4)$ & & $8.1(5.1-12.3)$ & & 0.814 \\
\hline Total testosterone (TT) (ng/dL) & $263(189-379)$ & & $269(109-372)$ & & 0.113 \\
\hline Free testosterone $(\mathrm{FT})(\mathrm{pg} / \mathrm{mL})$ & $5.4(3.7-7.5)$ & & $5.6(2.6-8.2)$ & & 0.7 \\
\hline PRL (ng/mL) & $10.3(7.6-15.4)$ & & $13.6(9.9-19.8)$ & & 0.006 \\
\hline ACTH (pg/mL) & $36.4(28.0-51.2)$ & & $27.5(19.8-34.9)$ & & $<0.001^{\dagger \dagger a}$ \\
\hline Cortisol ( $\mu \mathrm{g} / \mathrm{dL})$ & $10.0(7.3-12.6)$ & $10.2 \pm 4.1$ & $9.1(6.4-12.4)$ & $9.3 \pm 4.4$ & 0.136 \\
\hline $\mathrm{TSH}(\mu \mathrm{IU} / \mathrm{mL})$ & $0.69(0.40-0.96)$ & & $1.03(0.74-1.76)$ & & $<0.001^{\dagger \dagger \mathrm{a}}$ \\
\hline Free T4 (ng/dL) & $1.04(0.93-1.12)$ & & $0.82(0.66-0.93)$ & $0.81 \pm 0.20$ & $<0.001^{\dagger \dagger a}$ \\
\hline Maximum tumor diameter $(\mathrm{mm})$ & $14.4(11.6-18.7)$ & & $26.5(22.3-31.0)$ & $27.0 \pm 6.3$ & $<0.001^{\dagger \dagger \mathrm{a}}$ \\
\hline Microadenoma (<10 mm) & $16(14.3 \%)$ & & $0(0 \%)$ & & $<0.001^{\dagger \dagger \mathrm{b}}$ \\
\hline Macroadenoma ( $\geq 10 \mathrm{~mm})$ & $96(85.7 \%)$ & & $100(100 \%)$ & & \\
\hline Suprasellar extension & $37(33.0 \%)$ & & $100(100 \%)$ & & $<0.001^{\dagger \dagger \mathrm{b}}$ \\
\hline Knosp classification & $1(0-2)$ & & $1(1-2)$ & & $<0.001^{\dagger \dagger \mathrm{b}}$ \\
\hline 0 & $45(40.2 \%)$ & & $8(8 \%)$ & & \\
\hline 1 & $34(30.4 \%)$ & & $47(47 \%)$ & & \\
\hline 2 & $21(18.8 \%)$ & & $29(29 \%)$ & & \\
\hline 3 & $11(9.8 \%)$ & & $14(14 \%)$ & & \\
\hline 4 & $1(0.9 \%)$ & & $2(2 \%)$ & & \\
\hline
\end{tabular}

Data are expressed as medians with interquartile ranges (IQR) and means \pm SD for normally distributed parameters.

${ }^{\text {a }}$ Mann-Whitney $U$ test.

${ }^{\mathrm{b}}$ Fisher's exact test.

$\dagger<0.05, \dagger<0.01$

[20], respectively. The median FT was $5.4 \mathrm{pg} / \mathrm{mL}$, and 86 out of 112 patients $(76.8 \%)$ met the criterion of FT being lower than the Japanese age-specific reference range (Supplemental Table 1). We found a discrepancy between the number of patients with low TT and low FT in acromegaly. The numbers of patients with TT higher than $300 \mathrm{ng} / \mathrm{dL}$ and FT lower than the age-specific reference range were as follows: 0 of $15(0 \%)$ in their $20 \mathrm{~s}, 10$ of $41(24.4 \%)$ in their $30 \mathrm{~s}, 4$ of $27(14.8 \%)$ in their $40 \mathrm{~s}$, and 9 of $29(31.0 \%)$ in their $50 \mathrm{~s}$. The ratio of TT to FT slightly increased in an age-dependent manner $(\geq 40$ years) (Supplemental Fig. 1). No significant differences were observed in serum LH, FSH, TT, or FT between patients with acromegaly and NFPA. Tumor sizes were significantly smaller in patients with acromegaly than in those with NFPA (maximum tumor diameter, median 14.4 vs. $26.5 \mathrm{~mm}, p<0.001$ ). Microadenoma (maximum tumor diameter $<10 \mathrm{~mm}$ ) was detected $14.3 \%$ of patients with acromegaly and $0 \%$ of those with NFPA. The prevalence of suprasellar extension was $33 \%$ in patients with acromegaly and $100 \%$ in those with NFPA. In the Knosp classification, NFPA had a significantly higher degree of tumor invasion than acromegaly.

To identify the clinical parameters that correlated with the hypogonadal biomarkers, serum TT and FT, we examined the relationships between these biomarkers and clinical parameters, including age, BMI, various endocrine functions, the maximum tumor diameter, Knosp 
Table 2 Results of a correlation analysis of TT and FT in patients with acromegaly and non-functioning pituitary adenoma

\begin{tabular}{|c|c|c|c|c|c|c|c|c|}
\hline \multirow[b]{3}{*}{ Variables } & \multicolumn{4}{|c|}{ Acromegaly $(n=112)$} & \multicolumn{4}{|c|}{ NFPA $(n=100)$} \\
\hline & \multicolumn{2}{|l|}{$\mathrm{TT}$} & \multicolumn{2}{|l|}{ FT } & \multicolumn{2}{|c|}{ TT } & \multicolumn{2}{|c|}{ FT } \\
\hline & $r$ & $p^{\mathrm{a}}$ & $r$ & $p^{\mathrm{a}}$ & $r$ & $p^{\mathrm{a}}$ & $r$ & $p^{\mathrm{a}}$ \\
\hline Age & -0.005 & 0.958 & -0.25 & $0.008^{\dagger \dagger}$ & -0.182 & 0.0697 & -0.232 & $0.020^{\dagger}$ \\
\hline BMI & -0.301 & $<0.001^{\dagger \dagger}$ & -0.115 & 0.228 & -0.180 & 0.075 & -0.145 & 0.151 \\
\hline $\mathrm{GH}$ & -0.557 & $<0.001^{\dagger \dagger}$ & -0.493 & $<0.001^{\dagger \dagger}$ & 0.19 & 0.059 & 0.118 & 0.244 \\
\hline IGF-1 & -0.405 & $<0.001^{\dagger \dagger}$ & -0.196 & $0.039^{\dagger}$ & 0.408 & $<0.001^{\dagger \dagger}$ & 0.415 & $<0.001^{\dagger \dagger}$ \\
\hline IGF-1 (Z-score) & -0.426 & $<0.001^{\dagger \dagger}$ & -0.225 & $0.017^{\dagger}$ & 0.41 & $<0.001^{\dagger \dagger}$ & 0.411 & $<0.001^{\dagger \dagger}$ \\
\hline LH & 0.35 & $<0.001^{\dagger \dagger}$ & 0.292 & $0.002^{\dagger \dagger}$ & 0.41 & $<0.001^{\dagger \dagger}$ & 0.47 & $<0.001^{\dagger \dagger}$ \\
\hline FSH & 0.04 & 0.676 & -0.099 & 0.298 & 0.293 & $0.003^{\dagger \dagger}$ & 0.247 & $0.013^{\dagger}$ \\
\hline PRL & 0.107 & 0.263 & 0.086 & 0.369 & -0.200 & $0.046^{\dagger}$ & -0.281 & $0.005^{\dagger \dagger}$ \\
\hline ACTH & -0.006 & 0.948 & 0.107 & 0.268 & 0.397 & $<0.001^{\dagger \dagger}$ & 0.363 & $<0.001^{\dagger \dagger}$ \\
\hline Cortisol & 0.064 & 0.504 & 0.108 & 0.257 & 0.332 & $<0.001^{\dagger \dagger}$ & 0.499 & $<0.001^{\dagger \dagger}$ \\
\hline TSH & 0.154 & 0.106 & 0.226 & $0.017^{\dagger}$ & -0.155 & 0.133 & -0.132 & 0.202 \\
\hline Free $\mathrm{T} 4$ & 0.011 & 0.905 & -0.079 & 0.407 & 0.544 & $<0.001^{\dagger \dagger}$ & 0.6 & $<0.001^{\dagger \dagger}$ \\
\hline \multirow[t]{2}{*}{ Maximum tumor diameter } & -0.434 & $<0.001^{\dagger \dagger}$ & -0.39 & $<0.001^{\dagger \dagger}$ & -0.125 & 0.216 & -0.156 & 0.122 \\
\hline & $r$ & $p^{\mathrm{b}}$ & $r$ & $p^{\mathrm{b}}$ & $r$ & $p^{\mathrm{b}}$ & $r$ & $p^{\mathrm{b}}$ \\
\hline \multirow[t]{2}{*}{ Knosp classification } & -0.181 & 0.056 & -0.129 & 0.175 & -0.016 & 0.878 & -0.106 & 0.294 \\
\hline & Median (IQR) & $p^{\mathrm{c}}$ & Median (IQR) & $p^{\mathrm{c}}$ & & & & \\
\hline $\begin{array}{l}\text { Suprasellar extension - } \\
\text { Suprasellar extension }+\end{array}$ & $\begin{array}{l}291(201-425) \\
227(157-321)\end{array}$ & $0.031^{\dagger}$ & $\begin{array}{l}6.1(3.8-8.5) \\
4.6(3.2-6.3)\end{array}$ & $0.014^{\dagger}$ & & & & \\
\hline
\end{tabular}

Variables with skewed distributions were transformed to logarithmic data before being used in Pearson's correlation coefficient analyses.

a Pearson's correlation coefficient.

b Spearman's correlation coefficient.

${ }^{\mathrm{c}}$ Mann-Whitney $U$ test.

$\dagger<0.05, \dagger<0.01$

classification, and presence of suprasellar extension, using a single regression analysis or the Mann-Whitney $U$-test (Table 2). In patients with acromegaly, GH, IGF-1, IGF-1 (Z-score), LH levels, and the maximum tumor diameter all correlated with TT and FT levels. The presence of suprasellar extension was associated with lower TT and FT levels. The strongest correlation was observed between GH and TT $(r=-0.577, p<0.001)$ and FT $(r=-0.493, p<0.001)$ (Fig. 1a and 1b). A negative correlation between GH and FT was also observed when the subjects were limited to 16 patients with microadenoma (median GH $4.9 \mathrm{ng} / \mathrm{mL}$ and IQR 2.5$6.1 \mathrm{ng} / \mathrm{mL}$, median age 45 y.o. and IQR 34-50 у.о.), although the difference was not statistically significant $(r$ $=-0.458, p=0.075$ ). There was no correlation between $\mathrm{GH}$ and TT in the patients with microadenoma, which may be due to the small number of subjects, narrow range of $\mathrm{GH}$ values, and age-related differences in SHBG. When the subjects were extended to 75 patients with no suprasellar extension (median maximum tumor diameter $12.9 \mathrm{~mm}$ and IQR $10.7-15.5 \mathrm{~mm}$, median GH $10.3 \mathrm{ng} / \mathrm{mL}$ and IQR $4.9-17.8 \mathrm{ng} / \mathrm{mL}$, median age 41 y.o. and IQR 33-50 y.o.), significant negative correlation was observed between GH and TT $(r=-0.333, p=$ $0.003)$ and GH and FT $(r=-0.367, p=0.001)$. LH positively correlated with TT $(r=0.35, p<0.001)$ and FT $(r$ $=0.292, p=0.002$ ) (Fig. 1c and 1d). BMI correlated with TT, but not FT. Age and TSH correlated with FT, but not TT. Among these factors, age, BMI, GH, IGF-1, LH, PRL, TSH, and the maximum tumor diameter were selected as independent variables, and we identified critical factors associated with TT and FT using a multiple regression analysis (stepwise method). The results of the multiple regression analysis showed that $\mathrm{GH}$ had the strongest correlation with TT and FT (standardized partial regression coefficient $(\beta)$ for TT, $-0.387, p<0.001$, and $(\beta)$ for FT, $-0.384, p<0.001$, respectively) (Table 3 ). $\mathrm{GH}$ was a relevant factor even in other regression models excluding IGF-1 or the maximum tumor diameter. In patients with NFPA, IGF-1, IGF-1 (Z-score), LH, FSH, 

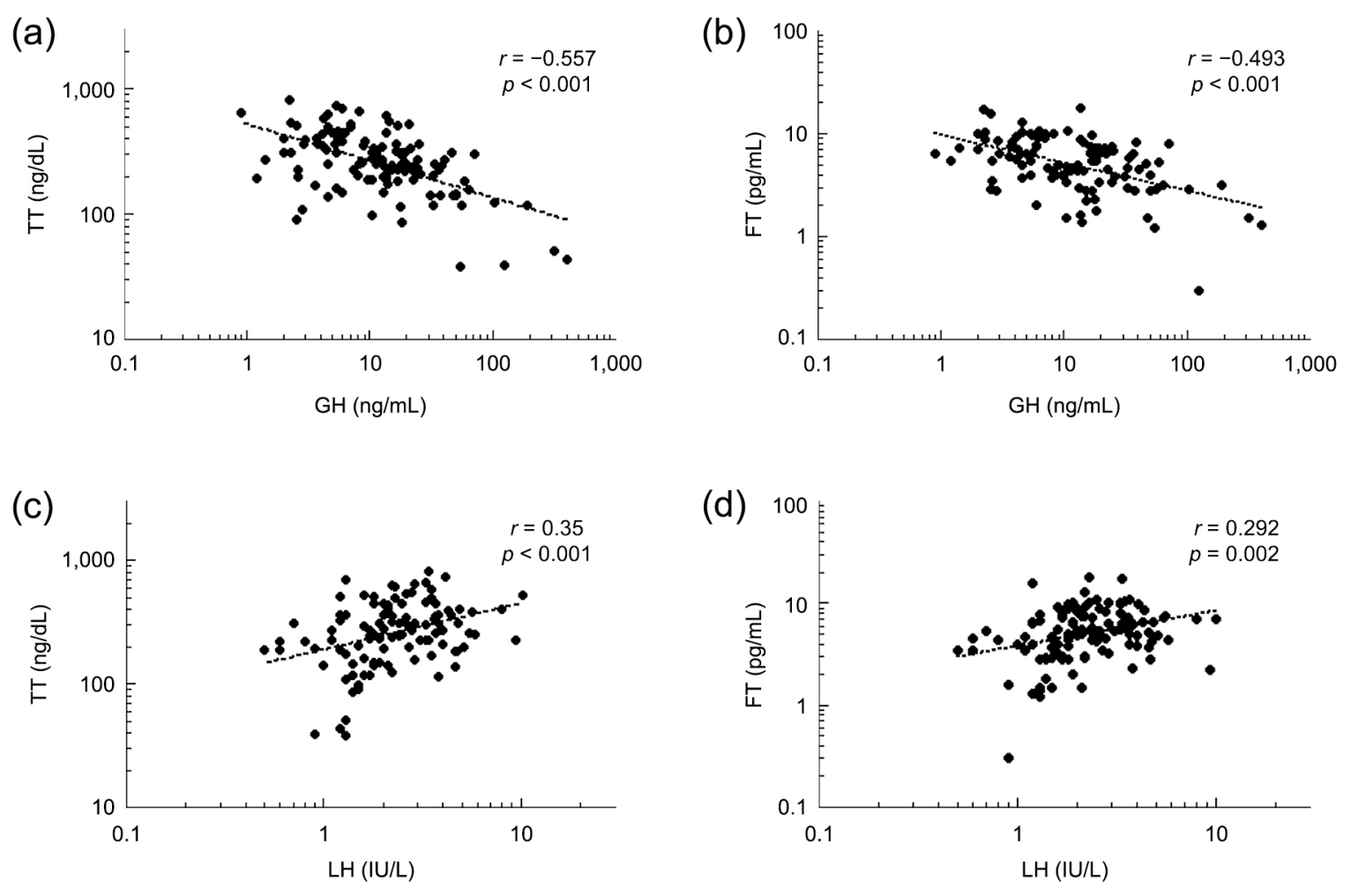

Fig. 1 Results of the correlation study on 112 male patients with acromegaly.

The graphs represent scatter diagrams between GH and TT (a), GH and FT (b), LH and TT (c), and LH and FT (d), which are summarized in Table 2.

PRL, ACTH, cortisol, and free T4 all correlated with TT and FT. IGF-1 or IGF-1 (Z-score) and TT or FT negatively correlated in patients with acromegaly, but positively correlated in those with NFPA. Age correlated with FT, but not TT. The strongest correlation was observed between free T4 and TT $(r=0.544, p<0.001)$ and FT $(r=0.600, p<0.001)$ (Table 2). Therefore, the degree of hypopituitarism correlated with TT and FT in patients with NFPA. We selected age, BMI, GH, IGF-1, LH, FSH, PRL, ACTH (for TT), cortisol (for FT), and free T4 as independent variables, and the multiple regression analysis revealed that LH showed the strongest correlation with TT and FT (standardized partial regression coefficient $(\beta)$ for TT, $0.349, p<0.001$, and ( $\beta$ ) for FT, 0.373, $p<0.001$, respectively) (Table 3).

The LH-RH loading test was performed both preoperatively and between days 7 and 14 postoperatively on 52 patients with acromegaly (Table 4 , left). In patients with NFPA, the test was rarely conducted preoperatively due to the large size of the tumor and the high risk of pituitary apoplexy, but was performed postoperatively in all 100 cases (Table 4, right). In patients with acromegaly, preoperative basal $\mathrm{LH}$, but not FSH, was significantly lower than that postoperatively (median $2.2 \mathrm{vs} .2 .9 \mathrm{IU} / \mathrm{L}$, $p<0.001$ ). However, the LH response against LH-RH appeared to be preserved preoperatively in patients with acromegaly because median maximum LH after the LHRH stimulation was $26.0 \mathrm{IU} / \mathrm{L}$ with a median 11.9 -fold increase. Therefore, basal LH secretion may be specifically suppressed in acromegaly. Comparisons of postoperative LH-RH loading test results between patients with acromegaly and NFPA showed that basal LH and FSH were significantly lower in those with NFPA and their response against LH-RH was blunted.

In acromegaly, 56 out of 112 patients were followed up for more than 6 months after surgery. Surgical remission was achieved endocrinologically in 49 out of 56 patients $(87.5 \%)$. Table 5 shows comparisons of various hormone levels in the 56 patients before and after surgery. Postoperative data were collected simultaneously during the postoperative period between 6 and 12 months. After surgery, median random GH levels significantly decreased from 13.5 (IQR 5.6-24.6) to 0.4 (IQR $0.1-1.5) \mathrm{ng} / \mathrm{mL}$, and median IGF-1 levels significantly decreased from 693 (IQR 601-931) to 185 (IQR 158226) $\mathrm{ng} / \mathrm{mL}$. TT in 45 patients $(80.4 \%)$ increased, median TT levels significantly increased from 267 (IQR 211-358) to 458 (IQR 311-535) ng/dL $(p<0.001)$ after surgery, and the number of hypogonadism patients with TT lower than $300 \mathrm{ng} / \mathrm{dL}$ decreased from 34 out of 56 
Table 3 Results of a multiple regression analysis of TT and FT in patients with acromegaly and non-functioning pituitary adenoma (NFPA)

\begin{tabular}{|c|c|c|c|c|c|}
\hline \multicolumn{6}{|c|}{ Acromegaly $(n=112)$} \\
\hline \multirow[b]{2}{*}{ Independent variables } & \multicolumn{2}{|l|}{ TT } & \multirow[b]{2}{*}{ Independent variables } & \multicolumn{2}{|l|}{ FT } \\
\hline & $\begin{array}{l}\text { Standardized partial } \\
\text { regression coefficient }(\beta)\end{array}$ & $p$ & & $\begin{array}{l}\text { Standardized partial } \\
\text { regression coefficient }(\beta)\end{array}$ & $p$ \\
\hline GH & -0.387 & $<0.001^{\dagger \dagger}$ & GH & -0.384 & $<0.001^{\dagger \dagger}$ \\
\hline BMI & -0.290 & $<0.001^{\dagger \dagger}$ & Age & -0.370 & $<0.001^{\dagger \dagger}$ \\
\hline LH & 0.255 & $0.001^{\dagger \dagger}$ & LH & 0.22 & $0.004^{\dagger \dagger}$ \\
\hline \multirow[t]{2}{*}{$\begin{array}{l}\text { Maximum tumor } \\
\text { diameter }\end{array}$} & -0.172 & $0.049^{\dagger}$ & TSH & 0.181 & $0.015^{\dagger}$ \\
\hline & & & $\begin{array}{l}\text { Maximum tumor } \\
\text { diameter }\end{array}$ & -0.200 & $0.024^{\dagger}$ \\
\hline \multicolumn{6}{|c|}{ NFPA $(n=89)$} \\
\hline \multirow[b]{2}{*}{ Independent variables } & TT & & \multirow[b]{2}{*}{ Independent variables } & \multicolumn{2}{|l|}{ FT } \\
\hline & $\begin{array}{l}\text { Standardized partial } \\
\text { regression coefficient }(\beta)\end{array}$ & $p$ & & $\begin{array}{l}\text { Standardized partial } \\
\text { regression coefficient }(\beta)\end{array}$ & $p$ \\
\hline LH & 0.349 & $<0.001^{\dagger \dagger}$ & LH & 0.373 & $<0.001^{\dagger \dagger}$ \\
\hline Free T4 & 0.284 & $0.003^{\dagger \dagger}$ & Cortisol & 0.33 & $<0.001^{\dagger \dagger}$ \\
\hline Age & -0.207 & $0.012^{\dagger \dagger}$ & Age & -0.302 & $<0.001^{\dagger \dagger}$ \\
\hline ACTH & 0.204 & $0.017^{\dagger}$ & Free $\mathrm{T} 4$ & 0.271 & $0.001^{\dagger \dagger}$ \\
\hline BMI & -0.162 & 0.05 & & & \\
\hline
\end{tabular}

$\dagger<0.05, \dagger<0.01$

Table 4 LH-RH loading test on patients with acromegaly and non-functioning pituitary adenoma (NFPA)

\begin{tabular}{|c|c|c|c|c|c|c|}
\hline & \multicolumn{2}{|c|}{ Acromegaly $(n=52)$} & \multirow{2}{*}{$p(\mathrm{a} v s . \mathrm{b})$} & \multicolumn{2}{|c|}{ NFPA $(n=100)$} & \multirow{2}{*}{$p(\mathrm{~b} v s . \mathrm{c})$} \\
\hline & Before surgery ${ }^{\mathrm{a}}$ & After surgery ${ }^{\mathrm{b}}$ & & Before surgery & After surgery $^{\mathrm{c}}$ & \\
\hline Basal LH (IU/L) & $2.2(1.7-2.8)$ & $2.9(2.0-3.8)$ & $<0.001^{\dagger \dagger}$ & N.A. & $2.1(1.1-3.0)$ & $<0.001^{i \dagger}$ \\
\hline Max LH (IU/L) & $26.0(20.5-32.8)$ & $20.4(16.2-24.7)$ & $<0.001^{\dagger \dagger}$ & N.A. & $8.3(4.4-13.4)$ & $<0.001^{\dagger \dagger}$ \\
\hline fold increase of LH & $11.9(8.1-18.6)$ & $7.1(5.4-8.8)$ & $<0.001^{\dagger \dagger}$ & N.A. & $4.2(3.3-5.2)$ & $<0.001^{\dagger \dagger}$ \\
\hline Basal FSH (IU/L) & $7.5(5.2-10.3)$ & $7.1(5.2-11.7)$ & 0.096 & N.A. & $5.5(3.5-7.7)$ & $0.001^{\dagger \dagger}$ \\
\hline Max FSH (IU/L) & $19.8(13.3-23.8)$ & $15.3(10.1-21.3)$ & $<0.001^{\dagger \dagger}$ & N.A. & $8.8(5.2-12.2)$ & $<0.001^{\dagger \dagger}$ \\
\hline Fold increase of FSH & $2.3(1.9-2.7)$ & $1.8(1.6-2.2)$ & $<0.001^{\dagger \dagger}$ & N.A. & $1.6(1.4-1.8)$ & $<0.001^{\dagger \dagger}$ \\
\hline
\end{tabular}

Data are expressed as medians with interquartile ranges (IQR). Postoperative data were collected simultaneously between 7 and 14 days after surgery. Statistical analyses of each change in the periods before and after surgery (a $v s . b)$ were performed using the Wilcoxon signed-rank test. The Mann-Whitney $U$ test was used to compare differences between patients with acromegaly and NFPA after surgery (b vs. c).

$\dagger<0.05, \pitchfork<0.01$

$(60.7 \%)$ before surgery to 11 out of $56(19.6 \%)$ after surgery (Supplemental Fig. 2). Similarly, FT in 49 patients $(87.5 \%)$ increased, median FT levels significantly increased from 5.7 (IQR 3.8-7.5) to 9.0 (IQR 7.811.5) $\mathrm{pg} / \mathrm{mL}(p<0.001)$, and the number of patients lower than the age-specific range decreased from 44 out of $56(78.6 \%)$ before surgery to 9 out of $56(16.1 \%)$ after surgery (Supplemental Fig. 3). PRL levels significantly decreased from 10.6 (IQR 7.3-17.0) to 7.2 (IQR 6.1-8.8) $\mathrm{ng} / \mathrm{mL}(p<0.001)$. However, correlations were not observed between the extent of changes before and after surgery in PRL $(\triangle \mathrm{PRL})$, TT $(\Delta \mathrm{TT})$, and FT $(\Delta \mathrm{FT})$ in the correlation analysis $(\Delta \mathrm{PRL}, \Delta \mathrm{TT}: r=-0.065, p=0.635$. $\Delta$ PRL, $\Delta \mathrm{FT}: r=-0.108, p=0.428)$. LH levels significantly increased from 2.3 (IQR 1.6-3.3) to 2.7 (IQR 1.93.7) $\mathrm{IU} / \mathrm{L}(p=0.024)$, while FSH levels significantly 
Table 5 Postoperative changes in various hormones in 56 patients with acromegaly and 60 with non-functioning pituitary adenoma (NFPA)

\begin{tabular}{|c|c|c|c|c|c|c|c|c|}
\hline & \multicolumn{3}{|c|}{ Acromegaly $(n=56)$} & \multicolumn{3}{|c|}{$\operatorname{NFPA}(n=60)$} & \multicolumn{2}{|c|}{$p^{c}$ (Acromegaly $v s$. NFPA) } \\
\hline \multirow[t]{2}{*}{ Age (y.o.) } & \multicolumn{3}{|c|}{$39(33-51)$} & \multicolumn{3}{|c|}{$48(41-54)$} & & \\
\hline & Before surgery & After surgery & $p^{\mathrm{a}}$ & Before surgery & After surgery & $p^{\mathrm{b}}$ & $\begin{array}{l}\text { Before } \\
\text { surgery }\end{array}$ & $\begin{array}{c}\text { After } \\
\text { surgery }\end{array}$ \\
\hline $\begin{array}{l}\text { GH } \\
(\mathrm{ng} / \mathrm{mL})\end{array}$ & $\begin{array}{c}13.5 \\
(5.6-24.6)\end{array}$ & $\begin{array}{c}0.4 \\
(0.1-1.5)\end{array}$ & $<0.001^{\dagger \dagger}$ & $\begin{array}{c}0.1 \\
(0.05-0.3)\end{array}$ & $\begin{array}{c}0.1 \\
(0.05-0.3)\end{array}$ & 0.747 & $<0.001^{\dagger \dagger}$ & $<0.001^{\dagger \dagger}$ \\
\hline $\begin{array}{l}\text { IGF-1 } \\
\text { (ng/mL) }\end{array}$ & $\begin{array}{c}693 \\
(601-931)\end{array}$ & $\begin{array}{c}185 \\
(158-226)\end{array}$ & $<0.001^{\dagger \dagger}$ & $\begin{array}{c}118 \\
(93-149)\end{array}$ & $\begin{array}{c}122 \\
(93-155)\end{array}$ & 0.76 & $<0.001^{\dagger \dagger}$ & $<0.001^{\dagger \dagger}$ \\
\hline $\begin{array}{l}\text { IGF-1 } \\
\text { (Z-score) }\end{array}$ & $\begin{array}{c}7.64 \\
(5.85-9.77)\end{array}$ & $\begin{array}{c}0.63 \\
(-0.41-1.25)\end{array}$ & $<0.001^{\dagger \dagger}$ & $\begin{array}{c}-0.91 \\
(-1.84--0.19)\end{array}$ & $\begin{array}{c}-0.91 \\
(-1.84--0.13)\end{array}$ & 0.771 & $<0.001^{\dagger \dagger}$ & $<0.001^{\dagger \dagger}$ \\
\hline $\begin{array}{l}\text { PRL } \\
(\mathrm{ng} / \mathrm{mL})\end{array}$ & $\begin{array}{c}10.6 \\
(7.3-17.0)\end{array}$ & $\begin{array}{c}7.2 \\
(6.1-8.8)\end{array}$ & $<0.001^{\dagger \dagger}$ & $\begin{array}{c}14.2 \\
(9.9-19.8)\end{array}$ & $\begin{array}{c}7.7 \\
(6.3-9.5)\end{array}$ & $<0.001^{\dagger \dagger}$ & 0.064 & 0.481 \\
\hline $\begin{array}{l}\text { Free T4 } \\
(\mathrm{ng} / \mathrm{dL})\end{array}$ & $\begin{array}{c}1.02 \\
(0.92-1.12)\end{array}$ & $\begin{array}{c}1.12 \\
(1.04-1.23)\end{array}$ & $<0.001^{\text {iो }}$ & $\begin{array}{c}0.86 \\
(0.74-0.99)\end{array}$ & $\begin{array}{c}0.99 \\
(0.89-1.06)\end{array}$ & $<0.001^{\dagger \dagger}$ & $<0.001^{\dagger \dagger}$ & $<0.001^{\dagger \dagger}$ \\
\hline $\begin{array}{l}\mathrm{LH} \\
(\mathrm{IU} / \mathrm{L})\end{array}$ & $\begin{array}{c}2.3 \\
(1.6-3.3)\end{array}$ & $\begin{array}{c}2.7 \\
(1.9-3.7)\end{array}$ & $0.024^{\dagger}$ & $\begin{array}{c}2.0 \\
(1.4-3.0)\end{array}$ & $\begin{array}{c}2.3 \\
(1.8-3.2)\end{array}$ & $<0.001^{\dagger \dagger}$ & 0.295 & 0.252 \\
\hline $\begin{array}{l}\mathrm{FSH} \\
(\mathrm{IU} / \mathrm{L})\end{array}$ & $\begin{array}{c}7.9 \\
(5.4-11.3)\end{array}$ & $\begin{array}{c}7.3 \\
(5.3-10.3)\end{array}$ & $<0.001^{\dagger \dagger}$ & $\begin{array}{c}7.9 \\
(6.2-10.8)\end{array}$ & $\begin{array}{c}6.5 \\
(5.1-9.3)\end{array}$ & $<0.001^{\dagger \dagger}$ & 0.908 & 0.744 \\
\hline $\begin{array}{l}\text { TT } \\
(\mathrm{ng} / \mathrm{dL})\end{array}$ & $\begin{array}{c}267 \\
(211-358)\end{array}$ & $\begin{array}{c}458 \\
(311-535)\end{array}$ & $<0.001^{\dagger \dagger}$ & $\begin{array}{c}290 \\
(146-418)\end{array}$ & $\begin{array}{c}338 \\
(279-465)\end{array}$ & $<0.001^{\dagger \dagger}$ & 0.695 & $0.015^{\dagger}$ \\
\hline $\begin{array}{l}\text { FT } \\
(\mathrm{pg} / \mathrm{mL})\end{array}$ & $\begin{array}{c}5.7 \\
(3.8-7.5)\end{array}$ & $\begin{array}{c}9.0 \\
(7.8-11.5)\end{array}$ & $<0.001^{\dagger \dagger}$ & $\begin{array}{c}6.1 \\
(3.6-8.4)\end{array}$ & $\begin{array}{c}8.9 \\
(6.7-11.2)\end{array}$ & $<0.001^{\dagger \dagger}$ & 0.675 & 0.347 \\
\hline
\end{tabular}

Data are expressed as medians with interquartile ranges (IQR). Postoperative data were collected simultaneously between 6 and 12 months after surgery. Statistical analyses of each change in the periods before and after surgery were conducted using the Wilcoxon signed-rank test (a and b). The Mann-Whitney $U$ test was used to compare differences between patients with acromegaly and NFPA (c).

$\dagger<0.05, \dagger+0.01$

decreased from 7.9 (IQR 5.4-11.3) to 7.3 (IQR 5.3-10.3) $\mathrm{IU} / \mathrm{L}(p<0.001)$. Postoperative data were obtained on 60 NFPA (TT from 60 patients and FT from 58 patients). It is important to note that the data of patients receiving androgen replacement therapy after surgery as well as those lost to the follow-up due to referrals were excluded. TT in 47 out of 60 patients (78.3\%) increased, median TT significantly increased from 290 (IQR 146418 ) to 338 (IQR 279-465) ng/dL $(p<0.001)$ after surgery, and the number of hypogonadism patients with TT lower than $300 \mathrm{ng} / \mathrm{dL}$ decreased from 32 out of 60 $(53.3 \%)$ before surgery to 20 out of $60(33.3 \%)$ after surgery. Similarly, FT in 45 out of 58 patients $(77.6 \%)$ increased, median FT significantly increased from 6.1 (IQR 3.6-8.4) to 8.9 (IQR 6.7-11.2) pg/mL $(p<0.001)$, and the number of patients with FT lower than the agespecific range decreased from 37 out of $59(62.7 \%)$ before surgery to 20 out of $58(34.5 \%)$ after surgery. PRL levels significantly decreased from 14.2 (IQR 9.919.8 ) to 7.7 (IQR 6.3-9.5) ng/mL ( $p<0.001)$. However, correlations were not observed between the extent of changes before and after surgery in PRL $(\triangle \mathrm{PRL})$, TT
$(\Delta \mathrm{TT})$, and $\mathrm{FT}(\Delta \mathrm{FT})$ in the correlation analysis $(\triangle \mathrm{PRL}$, $\Delta \mathrm{TT}: r=-0.082, p=0.532 . \Delta \mathrm{PRL}, \Delta \mathrm{FT}: r=-0.045, p=$ 0.732 ). LH significantly increased from 2.0 (IQR $1.4-$ 3.0 ) to 2.3 (IQR 1.8-3.2) IU/L $(p<0.001)$, while FSH significantly decreased from 7.9 (IQR $6.2-10.8$ ) to 6.5 (IQR 5.1-9.5) IU/L $(p<0.001)$. When pre- and postoperative gonadal functions (LH, FSH, TT, and FT) were compared between patients with acromegaly and NFPA, no significant differences were observed preoperatively. No significant differences were observed in LH, FSH, or FT postoperatively, whereas TT was significantly higher in patients with acromegaly. The cause of the discrepancy in TT after surgery between the two groups currently remains unclear, but may be partly due to increased SHBG with decreased GH in patients with acromegaly after surgery.

In patients with acromegaly, LH increased postoperatively in $36(64.3 \%)$, with TT increasing in $30(83.3 \%)$ and FT in $33(91.7 \%)$. On the other hand, in the 19 patients (33.9\%) with postoperative decreases in LH, TT increased in $14(73.7 \%)$ and FT in 15 (78.9\%). Difficulties are associated with explaining why the secretion of 

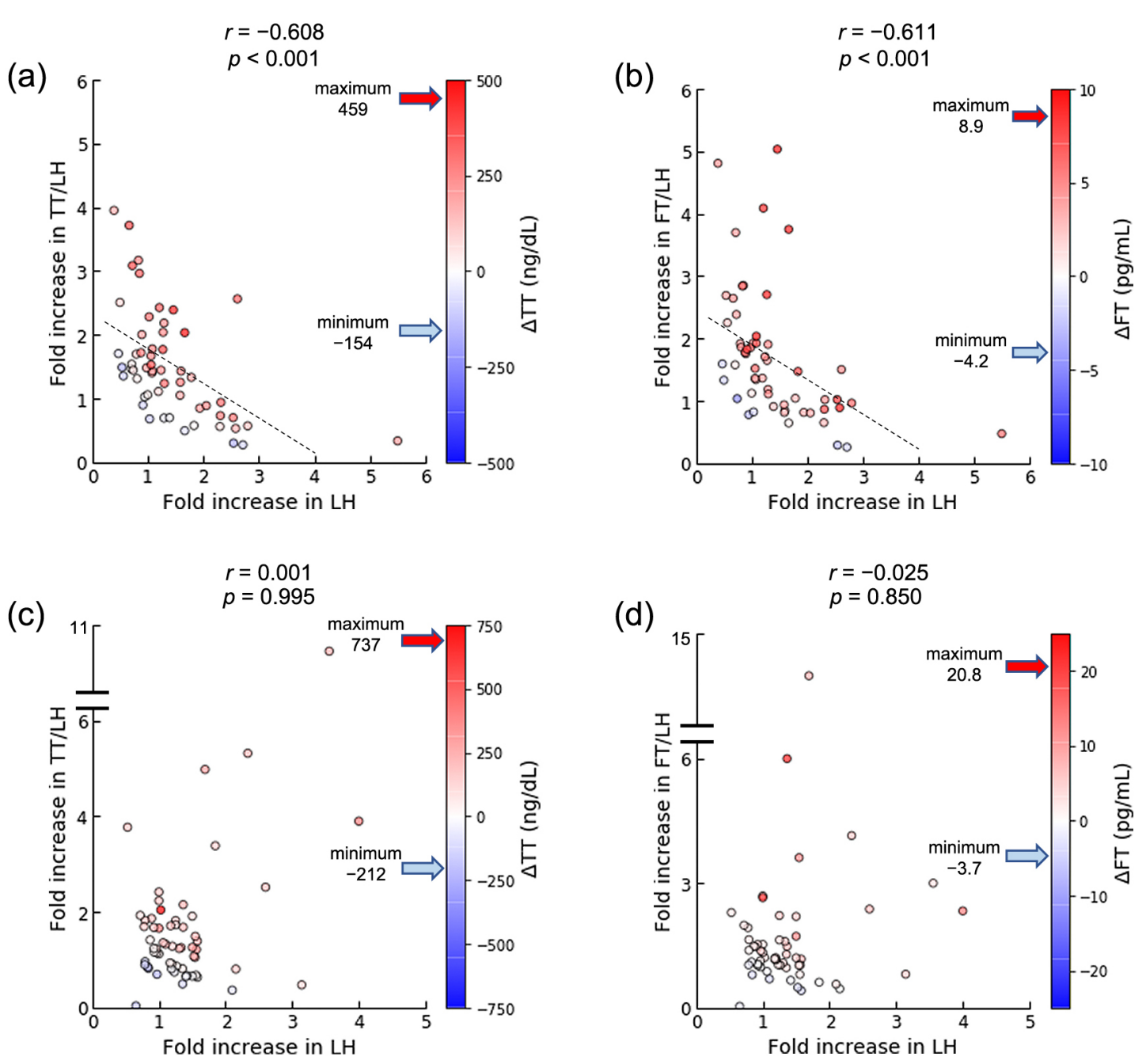

Fig. 2 Relationship between fold increases in LH and LH responsiveness (TT/LH or FT/LH) with changes in testosterone levels in 56 patients with acromegaly and 60 with non-functioning pituitary adenoma who were followed up after surgery.

The horizontal axis represents the fold increase in LH after surgery. The vertical axis represents the fold increase in the LH responsiveness shown by TT/LH in acromegaly (a), FT/LH in acromegaly (b), TT/LH in NFPA (c), or FT/LH in NFPA (d) after surgery. Colored circles shown by the heat map represent the increment in TT $(\Delta \mathrm{TT})(\mathrm{a}, \mathrm{c})$ or that in FT $(\Delta \mathrm{FT})(\mathrm{b}, \mathrm{d})$ after surgery. Patients with improved testosterone levels after surgery were shown in red, and those with worse levels were shown in blue. Relationships were assessed by Spearman's correlation coefficient.

TT and FT only increased with elevated LH after surgery because their levels increased in many patients showing a postoperative decrease in LH. Therefore, other potential factors were also considered, including LH responsiveness, indicating LH bioactivity and testicular responses to LH. Therefore, we investigated the TT/LH ratio as a potential parameter of LH responsiveness, and then compared the ratio between before and after surgery. The TT/LH and FT/LH ratios increased after surgery in $39(69.6 \%)$ and 40 patients $(71.4 \%)$ with fold increases of $1.50 \pm 0.84(p=0.02)$ and $1.68 \pm 1.05(p<$ $0.001)$, respectively. To clarify how the two factors, postoperative improvements in $\mathrm{LH}$ secretion and $\mathrm{LH}$ responsiveness, are involved in the recovery of testosterone levels, we plotted the fold increase in LH after sur- gery on the horizontal axis and that in TT/LH or FT/LH after surgery on the vertical axis in Fig. 2. Colored circles shown by the heat map represent $\Delta \mathrm{TT}$ or $\Delta \mathrm{FT}$. Patients with improved levels were shown in red, and those with worse levels were shown in blue. The fold increase in LH negatively correlated with those in $\mathrm{TT} / \mathrm{LH}(r=-0.607, p<0.001)$ and FT/LH $(r=-0.610, p$ $<0.001)$ in acromegaly. Patients showing good recovery were commonly observed when both factors increased after surgery. When one factor decreased postoperatively, the postoperative improvement in testosterone secretion required a greater increase in the other factor. Fold increases in TT/LH and FT/LH positively correlated with $\Delta \mathrm{TT}(r=0.546, p<0.001)$ and $\Delta \mathrm{FT}(r=0.475, p<$ 0.001 ), respectively, whereas that in LH did not (Supple- 
mental Fig. 4a-d). In patients with NFPA, no correlation was observed between the fold increase in LH and those in TT/LH and FT/LH. Fold increases in TT/LH and FT/LH positively correlated with $\Delta \mathrm{TT}(r=0.697, p<$ $0.001)$ and $\Delta \mathrm{FT}(r=0.719, p<0.001)$, respectively. In addition, the fold increase in LH positively correlated with $\Delta \mathrm{TT}(r=0.356, p=0.005)$ and $\Delta \mathrm{FT}(r=0.419, p<$ 0.001) (Supplemental Fig. 4e-h). Therefore, in patients with acromegaly, LH generally increases postoperatively, whereas the recovery of testosterone appears to be more accurately explained by an improvement in LH responsiveness than in by increases in its levels. In patients with NFPA, improvements in LH responsiveness and increases in its levels correlated with the recovery of testosterone.

\section{Discussion}

In the present study, we measured serum TT and FT levels in order to evaluate hypogonadism in men with acromegaly. TT includes testosterone that is bound to SHBG and albumin, with the approximately $2 \%$ remaining circulating as free testosterone. SHBG increases with aging, hyperthyroidism, and hyperestrogenemia, and decreases with excess GH, obesity, and insulin resistance [20]. The reference of the serum TT level does not have an age-specific range because SHBG increases with aging, while the reference of the serum FT level has an age-specific range because serum FT levels decrease with aging independent of increases in SHBG. Therefore, our single correlation analysis in Table 2 showed that BMI inversely correlated with TT, but not FT, whereas age inversely correlated with FT, but not TT. In addition to age, TSH positively correlated with FT, but not TT $(r=0.226, p=0.017)$. TSH levels in the present study were generally within the low normal range (median TSH $0.70 \mu \mathrm{IU} / \mathrm{mL}$, IQR $0.40-0.98$ ), which is consistent with TSH levels generally being low in patients with acromegaly [21]. However, the mechanisms by which serum TSH levels influence FT are very complex.

There is no generally accepted lower limit of normal TT levels. However, there is consensus that men with TT levels lower than $8 \mathrm{nmol} / \mathrm{L}(230 \mathrm{ng} / \mathrm{dL})$ generally benefit from testosterone replacement, while those with TT levels higher than $12 \mathrm{nmol} / \mathrm{L}(350 \mathrm{ng} / \mathrm{dL})$ do not need replacement [19]. A previous study reported that the frequency of hypogonadism in men with acromegaly with TT $<300 \mathrm{ng} / \mathrm{dL}$ was $49 \%$ [1] and with TT $<350 \mathrm{ng} / \mathrm{dL}$ was $42.8 \%$ [2]. In the present study, the frequencies of TT $<230 \mathrm{ng} / \mathrm{dL}$ and $<300 \mathrm{ng} / \mathrm{dL}$ were 38.4 and $57.1 \%$, respectively. The higher frequencies observed in the present study may be due to differences in race, the extent of excess GH, the severity of obesity, and/or variations among testosterone assay kits. The frequency of FT lower than the age-specific reference range was $76.8 \%$, which was markedly higher than that of TT $<300 \mathrm{ng} / \mathrm{dL}(57.1 \%)$. The present results showed that TT levels were slightly higher than FT levels in an agedependent manner (Supplemental Fig. 1), and patients with normal TT and low FT were more common among older patients. Although we did not measure SHBG levels in the present study because SHBG measurement is not covered by medical insurance in Japan, we speculate that age-dependent increases in SHBG may be attributed to the lower frequency of hypogonadism caused by TT, and that FT rather than TT may be a better biomarker for evaluating male hypogonadism in acromegaly. Other clinical data, such as erectile dysfunction, the loss of libido, and sperm findings will contribute to a more comprehensive evaluation of hypogonadism in acromegaly.

No significant differences were observed in the gonadal functions of LH, FSH, TT, and FT between patients with acromegaly and NFPA. However, patients with NFPA had low IGF-1 and significantly lower ACTH and free T4 than those with acromegaly. In addition, TT and FT positively correlated with not only LH and FSH, but also IGF1, ACTH, cortisol, and free T4 in patients with NFPA. In contrast, TT and FT in acromegaly negatively correlated with GH and IGF1 and positively correlated with LH. The multiple regression analysis identified $\mathrm{GH}$ as the strongest factor influencing TT and FT in patients with acromegaly. Patients with acromegaly had smaller tumors that were less invasive than those in patients with NFPA. Patients with NFPA who needed surgery presented with suprasellar extension in $100 \%$ of cases, whereas it was less frequent in those with acromegaly (33\%), which is consistent with previous findings showing that adenoma in patients acromegaly was more likely to extend downward [22]. Furthermore, comparisons of pre- and postoperative LH$\mathrm{RH}$ loading tests in patients with acromegaly showed that preoperative basal LH was suppressed, whereas the responsiveness of LH was preserved. These results are consistent with hypogonadism in NFPA being due to decreased LH, reflecting hypopituitarism caused by the tumor compressing the normal pituitary gland, whereas hypogonadism in acromegaly showed no obvious association with hypopituitarism, suggesting a relationship between the decrease in LH and excess GH rather than the compression of the normal pituitary gland by adenoma in patients with acromegaly.

The pathomechanisms underlying hypogonadism due to excess GH in acromegaly have not yet been elucidated in detail. However, several animal studies described the effects of excess $\mathrm{GH}$ on gonadal function. GH-transgenic 
fish, including tilapia [23], salmon [24], loach [25], and carp [26], have been developed as fast-growing genetically modified animals in aquaculture. Although the mechanism underlying $\mathrm{GH}$-mediated gonadal regulation in fish may differ from that in mammals, these GHtransgenic fish exhibit reduced courtship and spawning $[27,28]$, reduced sperm quantity and ovarian size [23, 29 ], and reduced nest loyalty, quivering frequency, and spawning participation [30]. In the GH-transgenic carp study, excess GH directly inhibited the expression and release of LH and FSH through GH receptors expressed in gonadotrophs. Furthermore, excess GH decreased hepatic leptin production, which appeared to reduce the leptin-mediated expression of $\mathrm{LH}$ and FSH [31]. In another study on GH-transgenic male mice, histological changes, such as tubules containing only Sertoli cells, tubules with arrested spermatogenesis, or vacuoles in the seminiferous epithelium, were noted in GH-transgenic mice, suggesting testicular aging. In addition, the immunohistochemical expression of LH receptors in Leydig cells decreased in GH-transgenic male mice, indicating that excess $\mathrm{GH}$ reduces the testicular response to $\mathrm{LH}$ in Leydig cells [32]. Collectively, these findings suggest that chronic excess GH suppresses the secretion of gonadotropin from the pituitary gland, accelerates testicular aging, and is associated with a testicular hyporesponse to LH in Leydig cells.

In the animal study [31], excess GH appeared to suppress the secretion of both LH and FSH. In a previous study on male hypogonadism in acromegaly, LH and FSH both significantly increased after surgery or a treatment with lanreotide [2]. However, in the present study, LH significantly increased, whereas FSH significantly decreased postoperatively in patients with acromegaly. Although the recovery of testosterone may reduce the production of $\mathrm{FSH}$, the reason(s) for this discrepancy currently remain unclear.

In the present study, $87.5 \%$ of patients achieved surgical remission, and TT and FT levels increased in more than $80 \%$ of patients. A significant increase in LH levels along with improved testosterone secretion was observed after surgery (median LH, 2.3 vs. $2.7 \mathrm{IU} / \mathrm{L}, p=0.024$; median TT, 267 vs. $458 \mathrm{ng} / \mathrm{dL}, p<0.001$; median FT 5.7 vs. $9.0 \mathrm{pg} / \mathrm{mL}, p<0.001)$. However, it currently remains unclear whether this increase solely contributed to the improvement observed in testosterone secretion after surgery. The GH-mediated suppression of LH secretion may not be a sufficient explanation as the mechanism responsible for hypogonadism in acromegaly. Regarding the acceleration of testicular aging by excess $\mathrm{GH}$, postoperative testosterone levels increased within 1 year of surgery, indicating that excess GH did not induce irreversible testicular aging. Regarding LH hyporespon- siveness in Leydig cells, approximately $70 \%$ of patients in the present study showed an increased TT/LH and $\mathrm{FT} / \mathrm{LH}$ ratios along with decreases in GH following surgery. Testicular hyporesponsiveness to LH may occur in Leydig cells, which is consistent with excess GH potentially reducing testicular responsiveness to LH [32]. Further studies are needed on the testicular expression of LH receptors in acromegaly. Central hypothyroidism in large NFPA is caused by the abnormal glycosylation of TSH, resulting in normal immunoreactivity, but reductions in the biological activity of TSH [33]. Since LH shares the same $\alpha$-subunit as TSH, large NFPA secretes abnormal LH with low bioactivity. However, it currently remains unclear whether excess $\mathrm{GH}$ induces the secretion of abnormal LH in patients with acromegaly.

In Fig. 2, we showed that the balance between improvements in $\mathrm{LH}$ and $\mathrm{LH}$ responsiveness to $\mathrm{LH}$ may affect the degree of recovery in postoperative testosterone levels. Various factors, such as preoperative GH levels, tumor sizes, compression of the normal pituitary gland, the postoperative status, bioactivity of $\mathrm{LH}$, and testicular responsiveness to LH, may coordinately influence the postoperative recovery of testosterone levels in patients with acromegaly.

The present study has several limitations. This was a retrospective study conducted at a single institute. Furthermore, the diagnosis of hypogonadism may require clinical symptoms and sperm functions in addition to serum TT and FT levels. In addition, we did not rule out the possibility of complications of hypogonadism unrelated to acromegaly, such as testicular disease. Disease duration plays an important role in pituitary function in patients acromegaly. However, due to insufficient patient information on disease duration in many cases, it was not included in the statistical analysis. Moreover, only 50\% of patients in the present study were examined postoperatively. We also did not investigate whether improvements in postoperative TT and FT levels affected the attenuation of clinical symptoms for hypogonadism. Finally, we did not evaluate the biological activity of LH in the present study.

In conclusion, excess serum GH itself had the strongest correlation with the decrease in testosterone in male patients with acromegaly without concomitant hyperprolactinemia. Impaired LH responsiveness (impaired LH bioactivity and/or testicular responsiveness to $\mathrm{LH}$ ) due to excess GH as well as the suppression of LH secretion may be responsible for hypogonadism in acromegaly, and these impairments may improve following successful surgery. 


\section{Disclosure}

None of the authors have any potential conflicts of interest associated with this research.

\section{Funding}

This work was supported by the Okinaka Memorial Institute for Medical Research to AT; JSPS KAKENHI (grant number 17K09895 and 20K08899 to AT).

\section{Author Declaration}

The manuscript is original and has not been submitted elsewhere. Each author acknowledges that he/she has contributed in a substantial way to the work described in the manuscript and it's preparation.
Supplemental Table 1 Reference range of free testosterone by age in the present study

\begin{tabular}{lc}
\hline Free testosterone & \\
\hline Age (y.o.) & Reference range $(\mathrm{pg} / \mathrm{mL})$ \\
\hline $20-29$ & $8.5-27.9$ \\
$30-39$ & $7.6-23.1$ \\
$40-49$ & $7.7-21.6$ \\
$50-59$ & $6.9-18.4$ \\
$60-69$ & $5.4-16.7$ \\
$70-79$ & $4.5-13.8$ \\
\hline
\end{tabular}

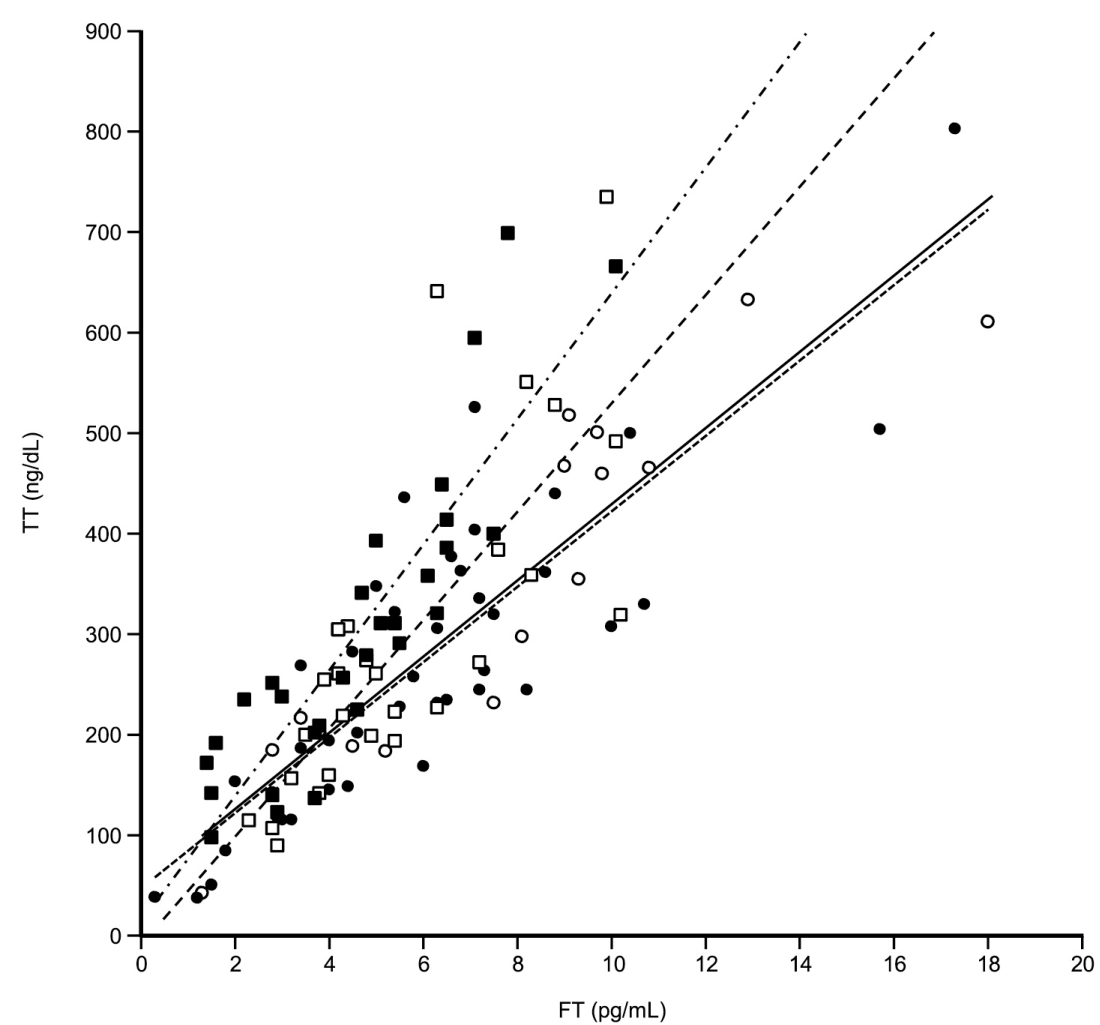

\begin{tabular}{|c|c|c|}
\hline $0-20-29$ y.o. $(n=15)$ & $y=37.945 x+50.192$ & $r^{2}=0.8219$ \\
\hline - $30-39$ y.о. $(n=41)$ & $y=37.544 x+46.811$ & $r^{2}=0.7317$ \\
\hline 口. - - 40-49 y.o. $(n=27)$ & $y=53.915 x-7.8383$ & $r^{2}=0.5994$ \\
\hline - . $-50-59$ y.o. $(n=29)$ & $y=62.746 x+13.427$ & $r^{2}=0.7821$ \\
\hline
\end{tabular}

Supplemental Fig. 1 Relationship between TT and FT levels and age in male patients with acromegaly.

We simultaneously measured TT and FT levels in the serum of 112 male patients with acromegaly and conducted a single regression analysis by age. The ratio of TT to FT was slightly higher in males older than 40 years. Open circle: $20-29$ years old $(n=15)$, filled circle: $30-39$ years old $(n=41)$, open square: $40-49$ years old $(n=27)$, filled square: 50-59 years old $(n=29)$. Solid line: 20-29 years old correlation, densely dashed line: 30-39 years old correlation, dashed line: 40-49 years old correlation, dash-dotted line: 50-59 years old correlation. 


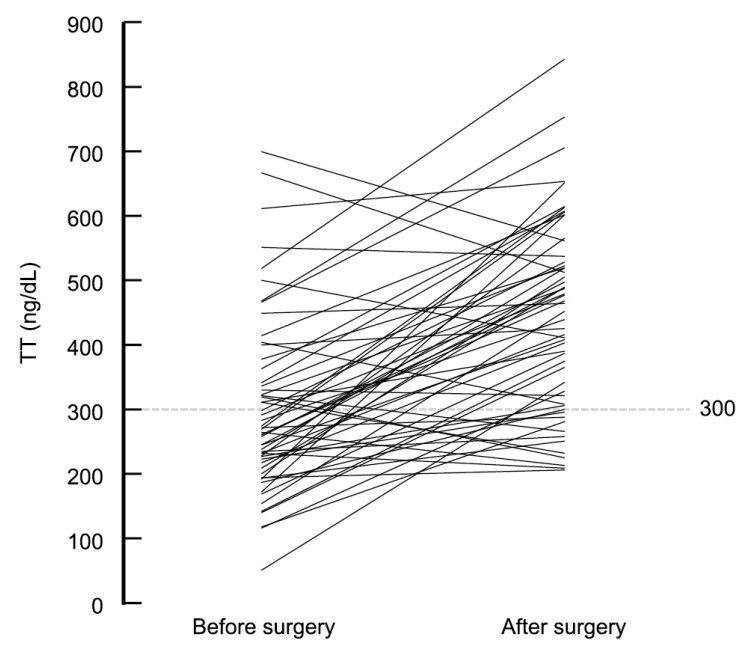

Supplemental Fig. 2 Changes in TT levels between before and after surgery in 56 male patients with acromegaly.

We measured and compared TT levels before and 6 to 12 months after surgery. The frequency of hypogonadism patients with TT levels lower than $300 \mathrm{ng} / \mathrm{dL}$ decreased from 34 out of $56(60.7 \%)$ before surgery to 11 out of $56(19.6 \%)$ after surgery. The dashed line represents the cut-off value for the hypogonadism criterion of TT lower than $300 \mathrm{ng} / \mathrm{dL}$.

(a)

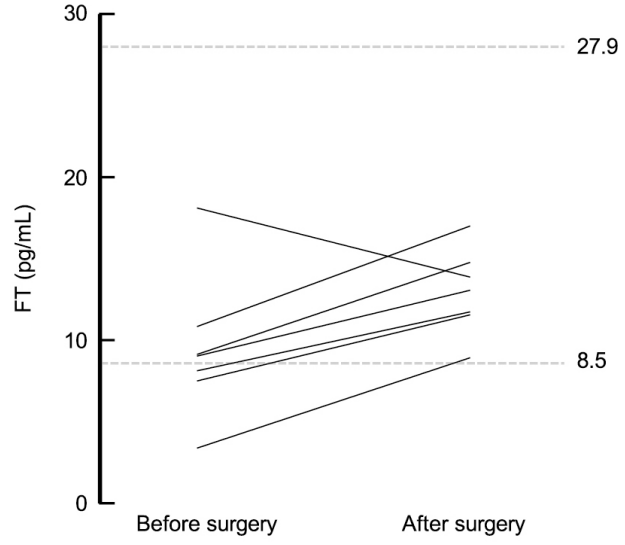

(c)

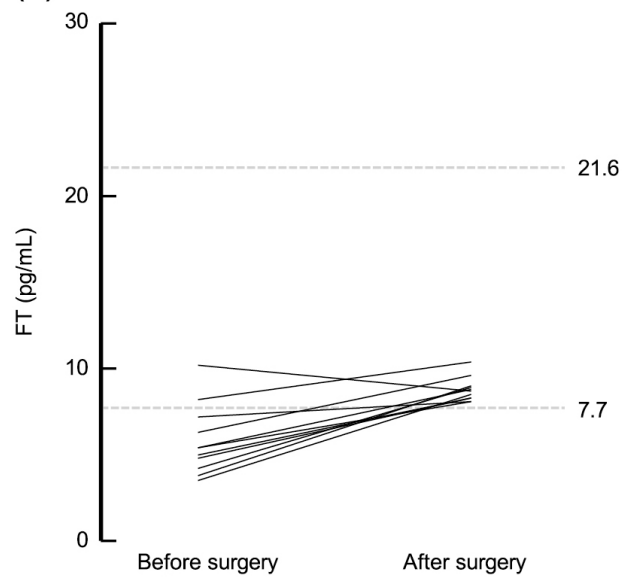

(b)

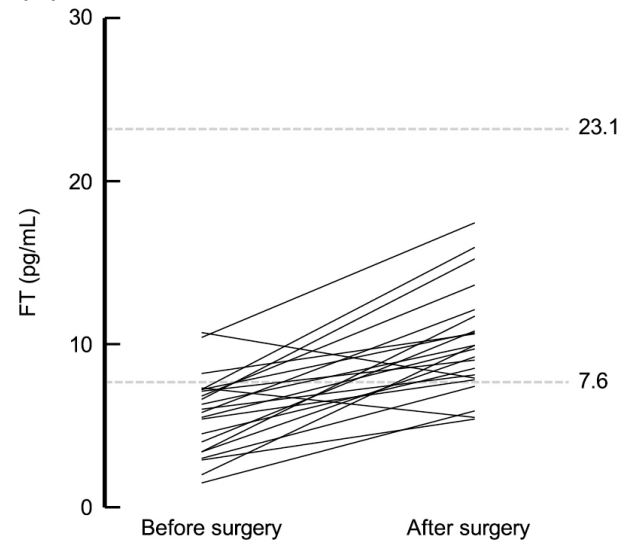

(d)

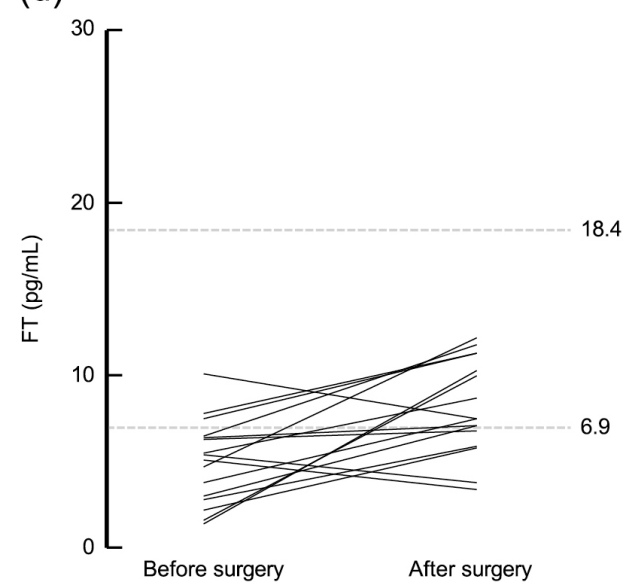

Supplemental Fig. 3 Changes in FT levels between before and after surgery by age in 56 male patients with acromegaly.

We measured and compared FT levels before and 6 to 12 months after surgery. (a): 20-29 years old, (b): 30-39 years old, (c): 40-49 years old, (d): 50-59 years old. The frequency of patients lower than the age-specific range decreased from 44 out of $56(78.6 \%)$ before surgery to 9 out of $56(16.1 \%)$ after surgery. The dashed line represents the cut-off values of the age-specific range for FT. 


\section{Acromegaly}

(a)

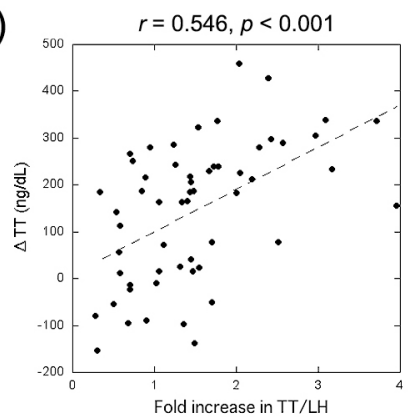

(c)

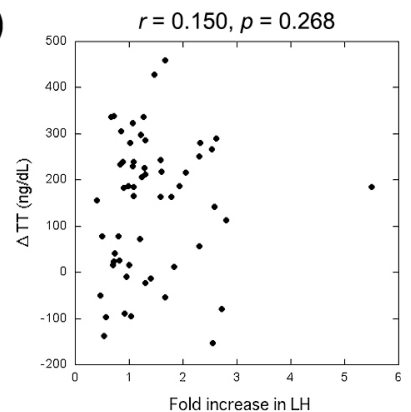

(b)

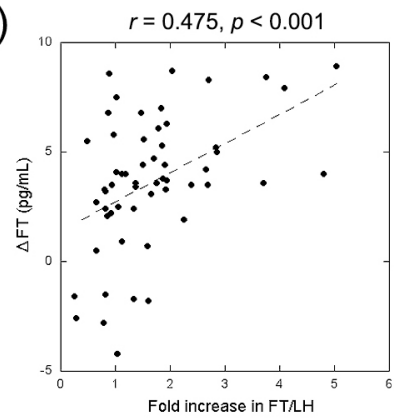

(d)

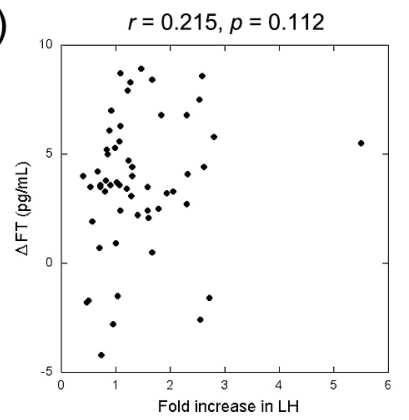

NFPA

(e)

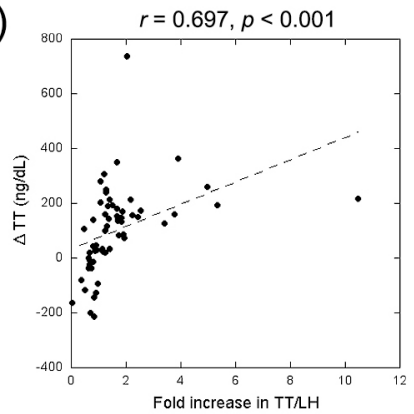

(g)

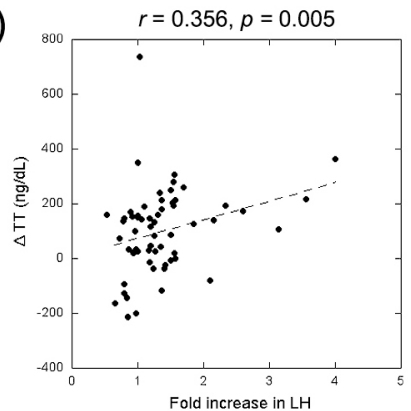

(f)

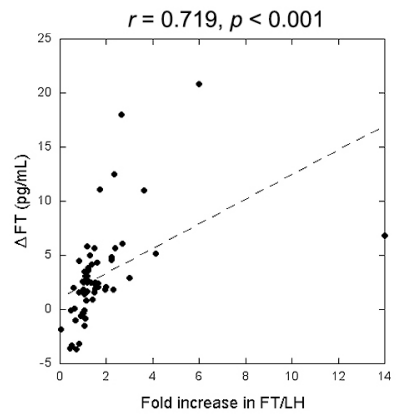

(h)

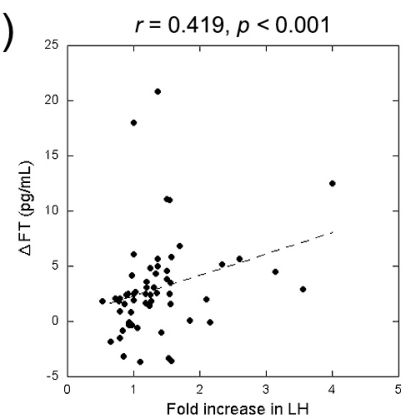

Supplemental Fig. 4 Relationship between fold increases in LH and changes in testosterone levels $(\Delta \mathrm{TT}$ or $\Delta \mathrm{FT})$ or between fold increases in TT/LH or FT/LH and changes in testosterone levels $(\Delta \mathrm{TT}$ or $\Delta \mathrm{FT})$ in 56 patients with acromegaly and 60 with non-functioning pituitary adenoma who were followed up after surgery. Realtionships were assessed by Spearman's correlation coefficient.

(a): Fold increase in TT/LH vs. $\Delta \mathrm{TT}$ in acromegaly, (b): fold increase in FT/LH vs. $\Delta \mathrm{FT}$ in acromegaly, (c): fold increase in LH vs. $\Delta \mathrm{TT}$ in acromegaly, (d): fold increase in LH vs. $\Delta \mathrm{FT}$ in acromegaly, (e): fold increase in TT/LH vs. $\triangle \mathrm{TT}$ in NFPA, (f): fold increase in FT/LH vs. $\triangle \mathrm{FT}$ in NFPA, (g): fold increase in LH vs. $\triangle \mathrm{TT}$ in NFPA, (h): fold increase in LH $v s . \triangle \mathrm{FT}$ in NFPA. 


\section{References}

1. Katznelson L, Kleinberg D, Vance ML, Stravou S, Pulaski $\mathrm{KJ}$, et al. (2001) Hypogonadism in patients with acromegaly: data from the multi-centre acromegaly registry pilot study. Clin Endocrinol (Oxf) 54: 183-188.

2. Colao A, De Rosa M, Pivonello R, Balestrieri A, Cappabianca P, et al. (2002) Short-term suppression of $\mathrm{GH}$ and IGF-I levels improves gonadal function and sperm parameters in men with acromegaly. J Clin Endocrinol Metab 87: 4193-4197.

3. Arafah BM (1986) Reversible hypopituitarism in patients with large nonfunctioning pituitary adenomas. J Clin Endocrinol Metab 62: 1173-1179.

4. Marazuela M, Astigarraga B, Vicente A, Estrada J, Cuerda C, et al. (1994) Recovery of visual and endocrine function following transsphenoidal surgery of large nonfunctioning pituitary adenomas. $J$ Endocrinol Invest 17: 703-707.

5. Lee CC, Chen CM, Lee ST, Wei KC, Pai PC, et al. (2015) Prediction of long-term post-operative testosterone replacement requirement based on the pre-operative tumor volume and testosterone level in pituitary macroadenoma. Sci Rep 5: 16194.

6. Sarkar DK, Yen SS (1985) Hyperprolactinemia decreases the luteinizing hormone-releasing hormone concentration in pituitary portal plasma: a possible role for $\beta$-endorphin as a mediator. Endocrinology 116: 2080-2084.

7. Magrini G, Ebiner JR, Burckhardt P, Felber JP (1976) Study on the relationship between plasma prolactin levels and androgen metabolism in man. $J$ Clin Endocrinol Metab 43: 944-947.

8. Galdiero M, Pivonello R, Grasso LFS, Cozzolino A, Colao A (2012) Growth hormone, prolactin, and sexuality. $J$ Endocrinol Invest 35: 782-794.

9. Hull KL, Harvey S (2000) Growth hormone: a reproductive endocrine-paracrine regulator? Rev Reprod 5: 175182.

10. Lobie PE, Breipohl W, Aragón JG, Waters MJ (1990) Cellular localization of the growth hormone receptor/binding protein in the male and female reproductive systems. Endocrinology 126: 2214-2221.

11. Chatelain PG, Sanchez P, Saez JM (1991) Growth hormone and insulin-like growth factor I treatment increase testicular luteinizing hormone receptors and steroidogenic responsiveness of growth hormone deficient dwarf mice. Endocrinology 128: 1857-1862.

12. Chandrashekar V, Bartke A, Awoniyi CA, Tsai-Morris $\mathrm{CH}$, Dufau ML, et al. (2001) Testicular endocrine function in GH receptor gene disrupted mice. Endocrinology 142: 3443-3450.

13. Chandrashekar V, Bartke A, Coschigano KT, Kopchick JJ (1999) Pituitary and testicular function in growth hormone receptor gene knockout mice. Endocrinology 140: 10821088.

14. Harvey S, Baumbach WR, Sadeghi H, Sanders EJ (1993) Ultrastructural colocalization of growth hormone binding protein and pituitary hormones in adenohypophyseal cells of the rat. Endocrinology 133: 1125-1130.

15. Carani C, Granata ARM, De Rosa M, Garau C, Zarrilli S, et al. (1999) The effect of chronic treatment with GH on gonadal function in men with isolated GH deficiency. Eur $J$ Endocrinol 140: 224-230.

16. Katznelson L, Laws ER, Melmed S, Molitch ME, Murad $\mathrm{MH}$, et al. (2014) Acromegaly: an endocrine society clinical practice guideline. J Clin Endocrinol Metab 99: 39333951 .

17. Giustina A, Chanson P, Bronstein MD, Klibanski A, Lamberts S, et al. (2010) A consensus on criteria for cure of acromegaly. J Clin Endocrinol Metab 95: 3141-3148.

18. Isojima T, Shimatsu A, Yokoya S, Chihara K, Tanaka T, et al. (2012) Standardized centile curves and reference intervals of serum insulin-like growth factor-I (IGF-I) levels in a normal Japanese population using the LMS method. Endocr J 59: 771-780.

19. Wang C, Nieschlag E, Swerdloff R, Behre HM, Hellstrom $\mathrm{WJ}$, et al. (2008) Investigation, treatment and monitoring of late-onset hypogonadism in males: ISA, ISSAM, EAU, EAA and ASA recommendations. Eur J Endocrinol 159: 507-514.

20. Basaria S (2014) Male hypogonadism. Lancet 383: 12501263.

21. Dạbrowska AM, Tarach JS, Kurowska M, Nowakowski A (2014) Thyroid diseases in patients with acromegaly. Arch Med Sci 10: 837-845.

22. Bier G, Hempel JM, Grimm F, Ernemann U, Bender B, et al. (2018) Quantification of specific growth patterns and frequency of the empty sella phenomenon in growth hormone-secreting pituitary adenomas. Eur J Radiol 104: 79-86.

23. Rahman MA, Mak R, Ayad H, Smith A, Maclean N (1998) Expression of a novel piscine growth hormone gene results in growth enhancement in transgenic tilapia (Oreochromis niloticus). Transgenic Res 7: 357-370.

24. Devlin RH, Biagi CA, Yesaki TY (2004) Growth, viability and genetic characteristics of GH transgenic coho salmon strains. Aquaculture 236: 607-632.

25. Nam YK, Cho YS, Cho HJ, Kim DS (2002) Accelerated growth performance and stable germ-line transmission in androgenetically derived homozygous transgenic mud loach, Misgurnus mizolepis. Aquaculture 209: 257-270.

26. Zhong C, Song Y, Wang Y, Li Y, Liao L, et al. (2012) Growth hormone transgene effects on growth performance are inconsistent among offspring derived from different homozygous transgenic common carp (Cyprinus carpio L.). Aquaculture 356-357: 404-411.

27. Bessey C, Devlin RH, Liley NR, Biagi CA (2004) Reproductive performance of growth-enhanced transgenic coho salmon. Trans Am Fish Soc 133: 1205-1220.

28. Fitzpatrick JL, Akbarashandiz H, Sakhrani D, Biagi CA, Pitcher TE, et al. (2011) Cultured growth hormone 
transgenic salmon are reproductively out-competed by wild-reared salmon in semi-natural mating arenas. Aquaculture 312: 185-191.

29. Rahman MA, Ronyai A, Engidaw BZ, Jauncey K, Hwang GL, et al. (2001) Growth and nutritional trials on transgenic Nile tilapia containing an exogenous fish growth hormone gene. J Fish Biol 59: 62-78.

30. Moreau DTR, Conway C, Fleming IA (2011) Reproductive performance of alternative male phenotypes of growth hormone transgenic Atlantic salmon (Salmo salar). Evol Appl 4: 736-748.

31. Chen J, Cao M, Zhang A, Shi M, Tao B, et al. (2018)
Growth hormone overexpression disrupts reproductive status through actions on leptin. Front Endocrinol (Lausanne) 9: 131.

32. Piotrowska K, Sluczanowska-Glabowska S, Kucia M, Bartke A, Laszczynska M, et al. (2015) Histological changes of testes in growth hormone transgenic mice with high plasma level of GH and insulin-like growth factor-1. Folia Histochem Cytobiol 53: 249-258.

33. Beck-Peccoz P, Rodari G, Giavoli C, Lania A (2017) Central hypothyroidism - a neglected thyroid disorder. Nat Rev Endocrinol 13: 588-598. 